\title{
The potential to improve growth rate and quality traits of stem straightness and branching habit when breeding Picea sitchensis (Bong.) Carr
}

\author{
Andrew D. Cameron • Stuart G. Kennedy • \\ Steven J. Lee
}

Received: 12 September 2011 / Accepted: 15 November 2011/Published online: 1 December 2011

(C) INRA / Springer-Verlag France 2011

\begin{abstract}
- Background Tree breeders continue to use visual assessments of stem shape and branching habit as part of their selection criteria because these are key features used by timber merchants in assessing stand value. However, it is not known how effective these assessments are in introducing real improvements in stem and branching traits to breeding and production populations of Sitka spruce. This study determined the genetic characteristics of several traits associated with stem straightness and branching, and examined whether these traits are suitable as future selection criteria.

- Methods Trees were sampled from 33 families selected from a 20 -year-old half-sibling progeny trial growing in northern Scotland and a control of directly imported material from Queen Charlotte Islands, Canada. Stem straightness and branching habit were 'scored' for quality
\end{abstract}

Handling Editor: Jean-Michel Leban

Contribution of co-authors The third author was involved in setting up the original progeny trial, assisted generally in the study and contributed to the drafting of the current paper. The second author carried out most of the field work and data analysis and some input into drafting the paper. The first author proposed the study, set up the funding and was involved in the study in its entirety. The manuscript has been largely drafted by the first author.

A. D. Cameron $(\bowtie) \cdot$ S. G. Kennedy

Institute of Biological and Environmental Sciences,

University of Aberdeen,

Cruickshank Building,

Aberdeen AB24 3UU, UK

e-mail: a.d.cameron@abdn.ac.uk

\section{S. J. Lee}

Forestry Commission,

Northern Research Station,

Roslin, Midlothian EH25 9SY, UK in addition to direct measurements made on growth and branching characteristics.

- Results Results indicate that heritability values for most external stem and branching properties evaluated visually are sufficiently strong to enable effective selection in tree improvement programmes. Estimated genetic correlations suggest that substantial improvements in branch and stem quality could be achieved without a reduction in growth rate. - Conclusions Visual scoring systems appear to successfully target families of good growth and small branch size relative to the control population.

Keywords Picea sitchensis . Stem and branch properties . Heritability. Phenotypic and genetic correlations

\section{Introduction}

Timber merchants assess the potential quantity, quality and value of sawlogs in standing trees primarily based on appearance in association with known characteristics in the sawmill. The key features of interest in the forest are stem straightness, relatively low taper and small 'flat' horizontal branches preferably not concentrated into strong whorls. Other features include lack of forking and absence of physical damage. Straight and largely cylindrical logs allow a high conversion percentage in the sawmill. Limiting particularly the size of knots, but also their number and distribution on the stem, ensures that the strength properties of sawn timber are not compromised. Not surprisingly, tree breeders have placed emphasis on external quality traits such as stem straightness and branching characteristics to improve sawlog quality and, consequently, the ultimate perceived economic value of trees when they are harvested. Improving stem straightness is a critical part of breeding 
strategies since the presence of stem crook, sweep and twist are known to be detrimental to wood quality resulting in the formation of compression wood and irregular grain (Ehrenberg 1970). Stem forking is also undesirable especially if it occurs near the tree base. Such stem defects reduce the volume and value of utilisable timber produced. The external branching properties of trees are closely related to knot development within the wood (Desch and Dinwoodie 1996). By reducing knot surface area and increasing knot spacing between whorls, the strength of sawn timber can be significantly improved. In addition, one large knot is generally considered to be more detrimental than a number of smaller knots of equivalent knot area (Maun 1992).

In Britain, a breeding programme for Sitka spruce (Picea sitchensis (Bong.) Carr.) was set up in 1963 with the aim of increasing productivity and improving timber quality for use in the construction industry (Fletcher and Faulkner 1972). The base population for the programme was from the Queen Charlotte Islands (QCI), British Columbia, Canada, since this location was found to be well matched with the cool maritime conditions found over much of the north and west of the British Isles (Samuel 2007). The breeding programme involved selecting individuals displaying superior vigour, stem straightness and wood density (Lee 1999). Data from replicated progeny tests across Britain led to reselection among the original plus trees of those parent individuals that had shown to be genetically most superior in terms of growth rate and stem form.

The reselected trees became the general breeding population that consists of individuals that maximise stem form and diameter whilst maintaining wood density at a level at least equivalent to that of the QCI base population (Lee 1999). A sophisticated scoring system was developed to allow visual assessment of individual stem straightness and branching characteristics of standing trees (Lee 1992, 1999). Objective assessments of each trait were rejected on the grounds of being too time-consuming and costly, and this has been the experience with loblolly pine (Pinus taeda L.) in southeast USA (Shelbourne and Namkoong 1966) and Venäläinen et al. (1995) with Scots pine (Pinus sylvestris L.) in Finland. Nevertheless, it is not known how effective this approach of subjective evaluation has been in introducing real improvements of stem and branching traits into the breeding and production populations. The aim of this study was to determine the heritability of stem and branching characteristics linked to sawlog quality and to establish which, if any, of these traits should be used as future non-destructive selection criteria in the Sitka spruce breeding programme. Correlations between these quality traits and various growth traits were also investigated to better understand how breeding for one trait may influence others under selection.

\section{Materials and methods}

\subsection{Experimental site}

In 1986, a half-sibling Sitka spruce progeny trial was established by Forest Research (an agency of the British Forestry Commission) in Scootmore Forest, Morayshire, Northern Scotland $\left(57^{\circ} 26^{\prime} \mathrm{N}, 3^{\circ} 23^{\prime} \mathrm{W}\right)$. The site is southfacing at an elevation of $200-250 \mathrm{~m}$ and is moderately exposed with an annual rainfall of 900-1,000 $\mathrm{mm}$. The soil is a peaty gley with an underlying geology of quartzose felspathic schistose flags. Prior to being ploughed for this experiment, the land use was treeless open heath dominated by Calluna vulgaris (L.). The progeny trial was planted at $2 \times 2$-m spacing $(2,500$ trees per hectare $)$ with 2 -year-old seedlings grown from open-pollinated seed collected from 68 plus trees. Families were planted in a complete randomised design. Each family was represented by eight trees planted in rows with five replicates, resulting in 40 planted trees per family. A standard QCI control of directly imported material was randomly located in three different rows within each replication. Replicates were further subdivided into sub-blocks using an 'Alpha design' to enable further removal of environmental variation within replicates (Williams and Matheson 1994).

Data previously collected by Forest Research for 15-year diameter at breast height (DBH measured at $1.3 \mathrm{~m}$ from the tree base), 10-year height, and 15-year branch and stem straightness scores were made available for this study. All other measurements were made at 20 years of age. The branching score system used in the British Sitka spruce breeding programme is a complex amalgam of different branching characteristics - size, angle, number, knot-tosurface area ratio-with no quantified weightings, that have largely been developed through discussions with the sawmilling industry. The problem for the practical tree breeder is that it takes too long to assess all these traits individually, especially if they vary in economic importance (which is often unknown) or are well correlated with other traits such that the performance of one trait can be deduced indirectly by the performance of another. Tree breeders find it more practical to develop an all-embracing visual assessment combining all these characteristics into just one subjective score. The emphasis is on branch size and number and less on branch angle. Trees within this experiment were subject to a branch and stem score assessment using the Forest Research visual assessment process. It involves a 1 to 6 system where ' 1 ' equates to the best branching quality or stem straightness and ' 6 ' the worst (Fig. 1). The scoring system used is not absolute, but is relative to the trees on the ground (i.e. the best and worst trees apply to the stand only), with the objective of scoring a normal distribution of scores as described by Cotterill and 


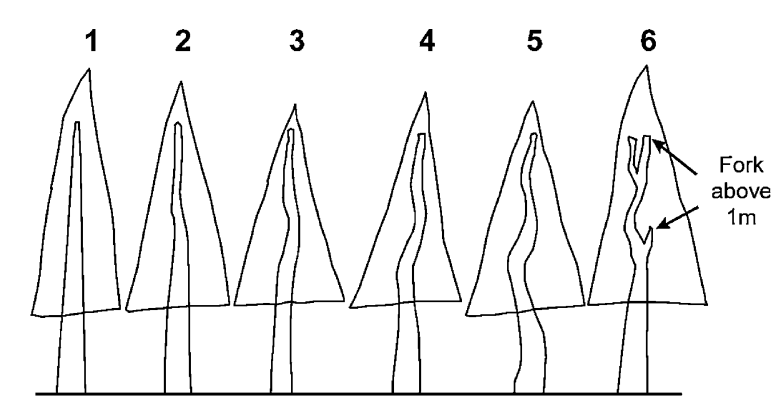

Straight no leader loss

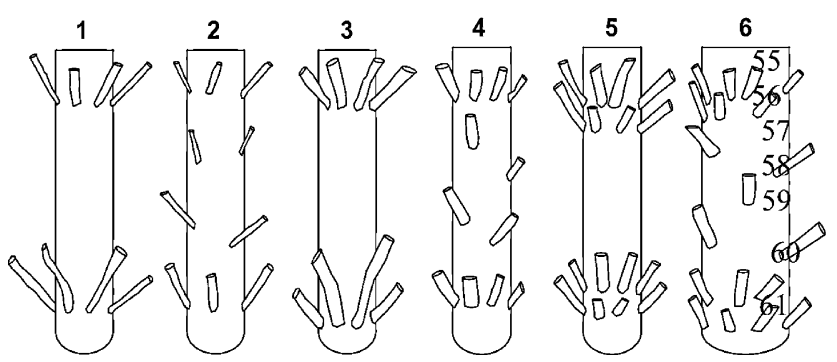

Fig. 1 Diagrammatic representation of stem (top) and branch (bottom) scoring systems (adapted from Lee unpublished). A score of 1 represents the best example for the site and 6 the worst. Branch angle was also considered when assigning branch scores (not represented in the figure)

Dean (1990). This scoring system was specifically designed to be applied to young individual trees $(<10 \mathrm{~m}$ tall, approximately 15 years old) and differs from the stand level method developed by Macdonald et al. (2009) to assess sawlog quality in mature stands.

\subsection{Sampling procedure}

Selection and felling of sample trees took place when the trees were 20 years old. The plus trees for 61 of the families planted within the progeny trial were of QCI origin, selected from a 40-year-old plantation in the Craigvinean block of Dunkeld Forest in Central Scotland (56 $34^{\prime} \mathrm{N}, 3^{\circ}$ $\left.39^{\prime} \mathrm{W}\right)$. The remaining seven families were of Alaskan origin and were excluded from the study. To ensure a representative selection of sample trees, poorly stocked families were also excluded. Given the time and financial resources available, a subsample of 33 families was randomly selected from the remaining 56 families. Three trees were randomly selected from each of the five replicates of the 33 families, i.e. 15 trees per family, in addition to 30 QCI control trees (totalling 525 trees). A measure of growth rate of the sample trees was made from $\mathrm{DBH}$ (diameter at $1.3 \mathrm{~m}$ ) assessed at 15 years old rather than 20 years old when the trees were felled. The assumption here is that a more representative expression of growth rate of the genotype is possible at 15 years old before excessive canopy competition occurs. Assessments of branch and stem score were made at 15 years of age for the same reason.
Sample trees were felled close to ground level and the branches removed up to the first complete living whorl at the base of the canopy. The distance between the butt end of the felled tree and the whorl formed in the last complete growing season towards the tip of the tree was also measured. The current year's height growth was not measured since trees were felled during the growing season. The distance between the butt end of the felled tree and the base of the first complete living whorl of branches was measured and subtracted from the tree's height to calculate depth of the living crown. The first complete living whorl was then removed as a complete section (approximately $15 \mathrm{~cm}$ in length) from each tree and the branches trimmed to leave small protrusions or 'pegs' approximately $10 \mathrm{~cm}$ in length (Fig. 2); branches $<5 \mathrm{~mm}$ in diameter were not included since these are not considered to have a meaningful influence on wood strength (e.g. Dinwoodie 2000). This whorl represented the maximum diameter of branch likely to be found on the tree within an area of potential sawlogs ( $<6 \mathrm{~m}$ from the base). The preferred option would have been to measure branch characteristics on a fixed whorl counted down from the top of the tree rather than the first complete living whorl, which is influenced by the depth of the crown. However, when stands have closed canopy for many years, the variation in canopy depth of individual trees would have meant that a fixed whorl may have been either within the living crown, and therefore the branches would not have attained their maximum size or that the whorl would have been below the

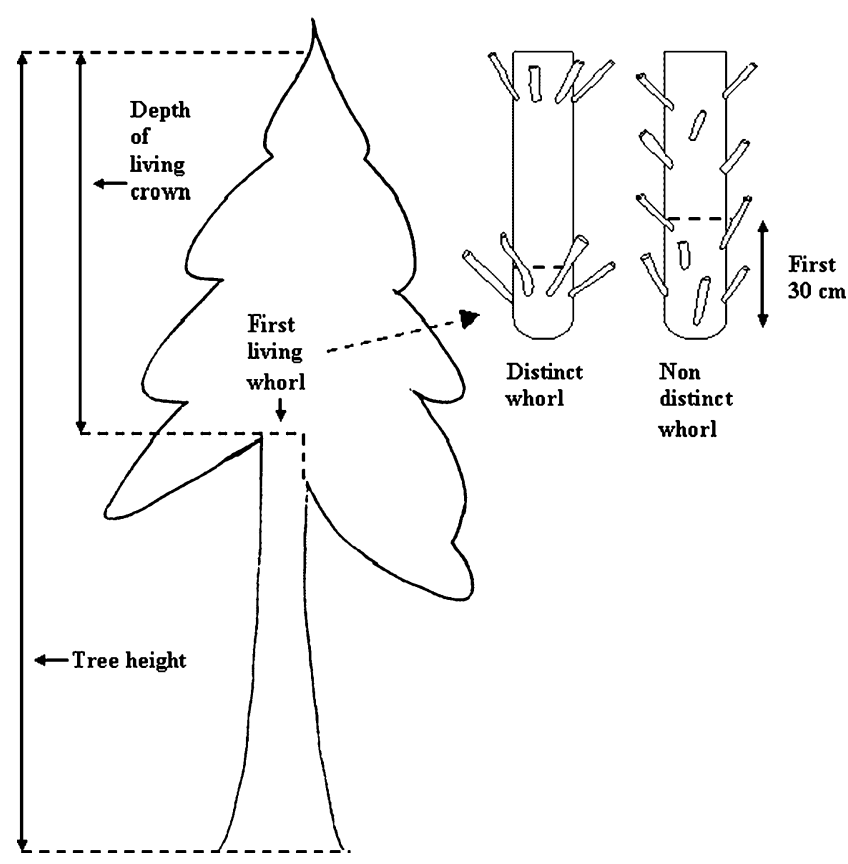

Fig. 2 Location of the first living whorl in the canopy. In trees where whorls were not distinct, the first complete living $30-\mathrm{cm}$ section was used 
living crown and branches either dead or lost. The assumption made here is that the whorl at the base of the crown represents the biggest branches (and knot size) that an individual tree will produce within the stand environment (one of the criteria that tree breeders use to make their selection) and that branch number and angle will not be greatly influenced by location within the stem.

Trees with double leaders or forks had the whorl removed from the larger stem. The number of branches in each section $>5 \mathrm{~mm}$ was also recorded. Where whorls were not distinct (i.e. branches spread over a length of stem rather than in a discrete cluster), branches were measured over a 30 -cm section of stem (Fig. 2).

\subsection{Statistical analyses}

Distributions of variables were sufficiently normal such that transformation was not necessary. Data were analysed using the statistical package SPSS 16.0. The QCI control was analysed separately from the family data to allow comparisons between the two groups.

The following linear model was used to carry out analysis of each trait measured.

$Y_{i j k l}=\mu+E_{i}+B_{i j}+f_{k}+f e_{i k}+p_{i j k}+w_{i j k l}$

(White and Hodge 1989)

where:

$\mu \quad$ a fixed general mean

$E_{i} \quad$ fixed effect of test environment $i$

$B_{i j} \quad$ fixed effect of replicate $j$ in test $i$

$f_{k} \quad$ random effect of family $k$

$f e_{i k} \quad$ random effect of family $k$ in test $i$

$P_{i j k} \quad$ random plot error of family $k$ in replicate $j$ in test $i$

$W_{i j k l} \quad$ random tree error of tree in plot $i j k$

Variance components were estimated using restricted maximum likelihood (REML), a mixed model analysis technique developed by Patterson and Thompson (1971).
Each tree was identified by family, replicate and sub-block (Alpha block). Environmental effects such as site and replicate where considered fixed whilst all other effects were random (after White and Hodge 1989). The estimated variance components were then used to calculate individual and family heritabilities and their respective standard errors for each trait using the relevant formula described by Wright (1976). Genetic correlations were also calculated for traits using the standard formula described by Williams and Matheson (1994). Phenotypic correlations were calculated using bivariate correlation.

\section{Results}

3.1 Mean and range of values of the measured traits

Details of the mean, minimum, maximum and coefficient of variation $(\mathrm{CV})$ for each measured trait are presented in Table 1 . In each case, the CV is relatively low (10-18\%), indicating that the traits measured are not particularly variable. This suggests that either the tree breeder successfully limited environmental variation when laying out the experiment or that there is limited genetic variation. Despite the stem score being assessed on a relative scale of 1 to 6 across the whole experiment, none of the trees within the subsample of 33 families were scored 6. This was a chance occurrence when the random subsample was made, with results being skewed towards the better end on the stem straightness spectrum, giving a trait mean of 2.79. Such skewness does not appear to be the case for the branching score, which has a commensurate higher trait mean value (3.49).

\subsection{Heritability}

Individual heritability $\left(h_{\mathrm{i}}^{2}\right)$ and family heritability $\left(h_{\mathrm{f}}^{2}\right)$ values are presented in Table 2 together with the estimated
Table 1 Mean, minimum, maximum values and coefficient of variation for growth traits (excludes QCI controls)

Subscript on the trait description is the tree age when the measurements were made. Coefficient of variation not calculated on count data. $N=$ number of trees

${ }^{\mathrm{a}}$ Branch and stem scores range from $1=$ best to $6=$ worst

\begin{tabular}{lccccc}
\hline Trait & $N$ & Mean & Minimum & Maximum & $\begin{array}{c}\text { Coefficient of } \\
\text { variation (\%) }\end{array}$ \\
\hline Height $_{10}(\mathrm{~m})$ & 492 & 4.54 & 3 & 6.4 & 14.70 \\
Height $_{20}(\mathrm{~m})$ & 495 & 12.52 & 8.2 & 15.8 & 10.71 \\
Crown depth $_{20}(\mathrm{~m})$ & 495 & 7.81 & 3.2 & 11.3 & 16.75 \\
DBH $_{15}(\mathrm{~cm})$ & 495 & 13.84 & 9.2 & 20.8 & 15.62 \\
Branch number $_{20}$ & 495 & 5.68 & 2 & 15 & - \\
Branch angle $_{20}(\mathrm{deg})$ & 495 & 68.62 & 33 & 89.62 & 11.95 \\
Branch diam.20 $_{20}(\mathrm{~mm})$ & 495 & 20.52 & 10.05 & 30.26 & 18.19 \\
Branch score $_{15}{ }^{\mathrm{a}}$ & 495 & 3.49 & 1 & 6 & - \\
Stem score $_{15}{ }^{\mathrm{a}}$ & 495 & 2.79 & 1 & 5 & - \\
\hline
\end{tabular}


Table 2 Estimated variance components calculated using REML along with their proportion of total phenotypic variance

\begin{tabular}{lcccccccc}
\hline Trait & $\sigma_{\mathrm{f}}^{2}$ & $\frac{\sigma_{\mathrm{f}}^{2}}{\sigma_{\mathrm{p}}^{2}} \times 100(\%)$ & $\sigma_{\mathrm{fr}}^{2}$ & $\frac{\sigma_{\mathrm{ff}}^{2}}{\sigma_{\mathrm{p}}^{2}} \times 100(\%)$ & $\sigma_{\mathrm{e}}^{2}$ & $\frac{\sigma_{\mathrm{e}}^{2}}{\sigma_{\mathrm{p}}^{2}} \times 100(\%)$ & $h_{\mathrm{i}}^{2}$ & $h_{\mathrm{f}}^{2}$ \\
\hline Height $_{10}(\mathrm{~m})$ & 0.028 & 6.98 & 0.045 & 11.22 & 0.328 & 81.80 & $0.28(0.032)$ & $0.48(0.123)$ \\
Height $_{20}(\mathrm{~m})$ & 0.205 & 14.31 & 0.063 & 4.40 & 1.165 & 81.30 & $0.57(0.045)$ & $0.69(0.174)$ \\
Crown depth $_{20}(\mathrm{~m})$ & 0.241 & 14.96 & 0.026 & 1.61 & 1.344 & 83.43 & $0.60(0.046)$ & $0.71(0.178)$ \\
DBH $_{15}(\mathrm{~cm})$ & 0.276 & 6.41 & 0.154 & 3.58 & 3.875 & 90.01 & $0.26(0.031)$ & $0.49(0.119)$ \\
Branch number $_{20}$ & 0.136 & 4.99 & 0.285 & 10.46 & 2.303 & 84.54 & $0.20(0.028)$ & $0.39(0.107)$ \\
Branch angle $_{20}\left({ }^{\circ}\right)$ & 9.084 & 13.69 & 0.000 & 0.00 & 57.293 & 86.31 & $0.55(0.044)$ & $0.70(0.170)$ \\
Branch diam.20 $_{20}(\mathrm{~mm})$ & 1.016 & 7.42 & 0.000 & 0.00 & 12.68 & 92.58 & $0.30(0.033)$ & $0.55(0.126)$ \\
Branch score $_{15}{ }^{\mathrm{a}}$ & 0.113 & 12.60 & 0.059 & 6.58 & 0.725 & 80.82 & $0.50(0.042)$ & $0.65(0.163)$ \\
Stem score $_{15}{ }^{\mathrm{a}}$ & 0.080 & 6.26 & 0.066 & 5.17 & 1.131 & 88.57 & $0.25(0.030)$ & $0.47(0.117)$ \\
\hline
\end{tabular}

Individual and family heritabilities calculated from the estimated variance components and their standard errors are also given in parentheses. Subscript on the trait description is the tree age when the measurements were made

$\sigma_{\mathrm{f}}^{2}=$ variation between family means

$\sigma_{f r}^{2}=$ family by replication interaction

$\sigma_{e}^{2}=$ environmental variation

$\sigma_{\mathrm{p}}^{2}$ (phenotypic variation) $=\sigma_{f}^{2}+\sigma_{f r}^{2}+\sigma_{\mathrm{e}}^{2}$

${ }^{\mathrm{a}}$ Branch and stem scores range from $1=$ best to $6=$ worst

variance components and their proportion of the total phenotypic variance. Family heritability was greater than the individual heritability for each trait. The heritability values for 15 -year diameter $\left(h_{\mathrm{f}}^{2}=0.49\right)$ and 10 -year tree height $\left(h_{\mathrm{f}}^{2}=0.48\right)$ are low, suggesting that they are under strong environmental control. Heritability values for crown depth are similar to those of 20-year tree height. Height would appear to have become more heritable with age since single-tree heritability values for 20-year height $\left(h_{\mathrm{i}}^{2}=0.57\right)$ are double that of 10 -year height $\left(h_{\mathrm{i}}{ }^{2}=0.28\right)$. Stem score was less heritable $\left(h_{\mathrm{i}}{ }^{2}=0.25\right.$ and $\left.h_{\mathrm{f}}{ }^{2}=0.47\right)$ than branch score which was moderately heritable $\left(h_{\mathrm{i}}{ }^{2}=0.50\right.$ and $h_{\mathrm{f}}{ }^{2}=$ $0.65)$. Branch angle heritability $(0.70)$ was moderately high, whilst branch number $\left(h_{\mathrm{f}}^{2}=0.4\right)$ and branch diameter $\left(h_{\mathrm{f}}^{2}=\right.$ $0.55)$ displayed a lower heritability.

\subsection{Phenotypic and genetic correlations}

Phenotypic correlations and genetic correlations $\left(r_{\mathrm{g}}\right)$ were estimated between pairs of traits (Table 3). The genetic correlations follow a similar pattern to the phenotypic correlations, but in general, genetic correlations were always stronger. Traits associated with growth rate were positively correlated with each other. For example, 10- and 20 -year height displayed a strong genetic correlation $\left(r_{\mathrm{g}}=\right.$ $0.79)$. Twenty-year tree height was also strongly correlated

Table 3 Genetic (below the diagonal) and phenotypic (above the diagonal) correlations between traits

\begin{tabular}{|c|c|c|c|c|c|c|c|c|c|}
\hline & $\begin{array}{l}\text { Height } \\
10(\mathrm{~m})\end{array}$ & $\begin{array}{l}\text { Height } \\
20(\mathrm{~m})\end{array}$ & $\begin{array}{l}\text { Crown depth } \\
20(\mathrm{~m})\end{array}$ & $\begin{array}{l}\text { DBH } \\
15(\mathrm{~cm})\end{array}$ & $\begin{array}{l}\text { Branch } \\
\text { number }\end{array}$ & $\begin{array}{l}\text { Branch } \\
\text { angle (deg) }\end{array}$ & $\begin{array}{l}\text { Branch } \\
\text { diam. (mm) }\end{array}$ & $\begin{array}{l}\text { Branch } \\
\text { score }^{\mathrm{a}}\end{array}$ & $\begin{array}{l}\text { Stem } \\
\text { score }^{\mathrm{a}}\end{array}$ \\
\hline Height $_{10}(\mathrm{~m})$ & & 0.64 & 0.48 & 0.71 & -0.01 & 0.14 & 0.45 & -0.07 & -0.33 \\
\hline Height $_{20}(\mathrm{~m})$ & 0.79 & & 0.74 & 0.55 & -0.06 & 0.04 & 0.38 & -0.08 & -0.19 \\
\hline Crown depth $20(\mathrm{~m})$ & 0.59 & 0.93 & & 0.43 & -0.01 & 0.14 & 0.36 & -0.09 & -0.22 \\
\hline $\mathrm{DBH}_{15}(\mathrm{~cm})$ & 0.69 & 0.54 & 0.28 & & 0.07 & 0.14 & 0.53 & 0.21 & -0.21 \\
\hline Branch number 20 & -0.47 & -0.76 & -0.60 & -0.11 & & 0.10 & -0.23 & 0.11 & 0.01 \\
\hline Branch angle $_{20}(\mathrm{deg})$ & 0.19 & 0.02 & 0.16 & 0.20 & 0.83 & & -0.11 & -0.10 & 0.02 \\
\hline Branch diam.20 $_{.2 \mathrm{~mm}}$ & 0.79 & 0.74 & 0.70 & 0.49 & -1.04 & 0.07 & & 0.00 & -0.20 \\
\hline Branch score $_{15}{ }^{\mathrm{a}}$ & -0.17 & -0.62 & -0.41 & 0.05 & 0.42 & -0.32 & -0.32 & & 0.27 \\
\hline Stem score $_{15}{ }^{\mathrm{a}}$ & -0.41 & -0.42 & -0.35 & 0.11 & 0.54 & 0.19 & 0.01 & 0.28 & \\
\hline
\end{tabular}

Subscript on the trait description is the tree age when the measurements were made

${ }^{\mathrm{a}}$ Branch and stem scores range from $1=$ the best to $6=$ worst 
with depth of crown $\left(r_{\mathrm{g}}=0.93\right)$ and branch diameter $\left(r_{\mathrm{g}}=\right.$ $0.74)$. However, branch number had a strong negative genetic correlation with 20-year height $\left(r_{\mathrm{g}}=-0.76\right)$ and branch diameter $\left(r_{\mathrm{g}}=-1.04\right)$, suggesting that taller trees have proportionally bigger crowns with fewer but larger branches; shorter trees have proportionally smaller crowns with a larger number of smaller branches. Branch angle displayed a strong correlation $\left(r_{\mathrm{g}}=0.83\right)$ with branch number, indicating that trees with many branches have less acute branching habits compared with trees with fewer branches. The correlation between branch angle and 15year DBH $\left(r_{\mathrm{g}}=0.20\right)$ was favourable but weak.

Traits were categorised by stem score and compared. Figure 3 shows that trees with a better stem score had both a significantly larger DBH and branch diameter when compared with trees with a poorer stem score $(p=0.001)$. Similarly, traits were also categorised by branch score (information not presented here). The visual amalgam of 'branch' score was not found to be significantly correlated with any one of the branching traits measured in this study, although there was a moderate correlation with branch number $\left(r_{\mathrm{g}}=0.42\right)$ and slightly weaker correlation with branch angle and branch diameter $\left(r_{\mathrm{g}}=0.32\right)$. However, trees with a larger DBH were found to have a significantly better branch score compared with trees with a smaller DBH $(p<0.005)$.

\section{Discussion}

\subsection{Heritability of growth and stem form traits}

Previous studies have investigated the genetics of tree height and stem diameter of Sitka spruce (Samuel and Johnston 1979; Lee et al. 2002). Briefly, they found heritabilities of 15-year DBH and 10-year height $\left(h_{\mathrm{f}}^{2}=\right.$ 0.58 and 0.55$)$ similar to those reported here $\left(h_{\mathrm{f}}^{2}=0.49\right.$ and 0.48). A similar strong genetic correlation $\left(r_{\mathrm{g}}=0.80\right)$ between 10-year height and 15-year DBH was also found

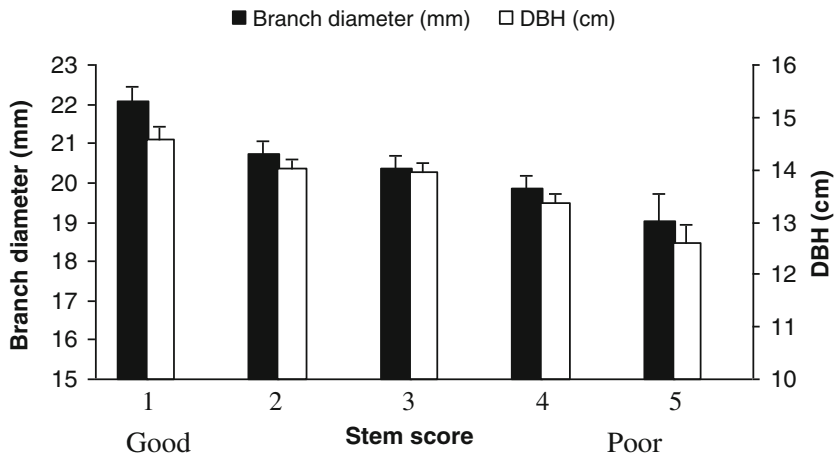

Fig. 3 Average branch diameter and DBH for trees assigned to each stem score
(Lee et al. 2002). Tree height was not measured in earlier studies beyond around 10 years after planting due to the difficulty in accurate measurement, so instead DBH measurements were taken to assess growth. The destructive nature of this study offered an opportunity to make detailed height measurements of trees aged 20 years. Tree height was found to become more heritable with age. An increase in family heritability from 0.48 to 0.69 occurred between 10 and 20 years of age. At age 20, the stand had closed canopy and trees were in direct competition with one another. It is quite likely that these competition differences are being confounded with genetic differences between trees, so inflating estimates of heritability.

The visual assessment of branching is a complex trait taking into consideration branch number, branch diameter and branch angle. No single branching factor measured in this study was found to control overall branch score, suggesting that a combination of branching traits are important to determining good branching quality as assessed using the subjective scoring protocol. This study found 15-year branch and stem scores to be moderately heritable $\left(h_{\mathrm{f}}^{2}=0.65\right.$ and 0.47 respectively), whilst Lee (1999) estimated a family heritability of 0.70 for stem form (a combination of branch and stem scores) based on a much larger sample size of 700 Sitka spruce families between 15 and 22 years of age. Elsewhere, reports of genetic control over stem straightness assessed subjectively using a scoring system similar to that used in this study show great variability varying from $h_{\mathrm{f}}^{2}=0.70$ with 8 -year-old loblolly pine (Williams and Lambeth 1989) using a 1 to 6 scale through to $h^{2}=0.03$ and 0.15 in Pinus radiata (D) Don. and Pinus elliottii Engel. (respectively) reported by Cotterill et al. (1987) using a 1 to 8 scale. Haapanen et al. (1997) reported an individual tree heritability of 0.12 in Scots pine measured subjectively on a 1 to 5 score. Quantitative stem straightness assessments of trees in genetic trials by means such as deviations from the vertical relative to a plumb or laser line down the tree have not been reported in the literature to our knowledge, presumably on grounds of time, cost and feasibility. Visual assessment is quick, can combine a number of different branching or stem straightness traits into one variable, which can in turn be included in a multi-trait selection index along with other characteristics of economic importance such as stem diameter and measures of timber strength.

Of the individual traits assessed that contribute to branching quality, branch angle was found to be the most heritable $\left(h_{\mathrm{f}}^{2}=0.72\right)$. Other studies have found similar family heritabilities $(0.65-0.92)$ for branch angle in Douglas fir (Pseudotsuga menziesii (Mirb.) Franco) and white spruce (Picea glauca (Moench) Voss; Merrill and Mohn 1984; King et al. 1992; Vargas-Hernandez et al. 2003). Haapanen et al. (1997) also found branch angle to 
have the highest individual heritability amongst 16 Scots pine progeny tests growing in Finland, which concurred with earlier similar studies by Velling and Tigerstedt (1984). By comparison, branch diameter and branch number in this study were found to be less heritable than branch angle, in agreement with other works (Bailey et al. 1974; Merrill and Mohn 1984), suggesting that they are under less genetic control.

\subsection{Genetic correlations}

The genetic correlations found between branching and growth traits indicate that selection of larger trees will result in progenies with fewer but larger branches per whorl compared with smaller trees that have finer but more numerous branches per whorl. Branch diameter was correlated with 10 -year tree height $\left(r_{\mathrm{g}}=0.79\right)$ and 15 -year DBH $\left(r_{\mathrm{g}}=0.49\right)$, indicating that bigger trees have bigger branches. This has been observed previously in Sitka spruce (Cameron et al. 2005) and noble fir (Abies procera Rehd.; Doede and Adams 1998) progenies of differing growth rates. Haapanen et al. (1997) also found moderate positive correlations between branch diameter and tree height between Scots pine progenies, with again a lower correlation between branch diameter and stem diameter. Trees with a greater number of branches per whorl had branches of a smaller diameter. A similar negative genetic correlation between branch number and branch diameter $(-0.82)$ was reported for Virginia pine (Pinus virginiana Mill.; Bailey et al. 1974) and white spruce (-0.73; Merrill and Mohn 1984).

Branch angle was found to have a strong genetic correlation with branch number $\left(r_{\mathrm{g}}=0.83\right)$, indicating that trees with fewer branches have branches with more acute angles to the stem. The concern is that an increasingly acute branch angle will result in a greater knot volume for a given branch diameter and, consequently, the greater likelihood that it will influence timber strength (Maun 1992). Bailey et al. (1974) also found branch angle to be strongly correlated with branch number (1.03) in Virginia pine. However, Merrill and Mohn (1984) found a weak negative correlation $(-0.39)$ for white spruce. Despite the strong correlation found between branch angle and branch number, no such correlation was found between branch angle and branch diameter $\left(r_{\mathrm{g}}=0.07\right)$ or branch angle and stem diameter $\left(r_{\mathrm{g}}=\right.$ $0.20)$ in this study. Only the first living whorl of each tree was considered when making branching measurements, which did not take account of inter-whorl branches. Such sampling methods are unlikely to affect branch diameter and branch angle measurements, but could introduce errors when estimating branch number, so the genetic linkage expressed between branch angle and branch number $\left(r_{\mathrm{g}}=\right.$ 0.83 ) should be treated with caution.
Taller trees were found to have significantly better branch and stem scores, enabling improvements in all these traits through selection and breeding. The more dominant larger trees will have achieved a competitive advantage over subdominant smaller trees by the mid-rotation age of this trial. Initial fast growth due to microenvironment or genetic stock is the likely mechanism for the dominance of an individual tree. It is likely that most trees with poor stem form, such as forking or excessive branching, would tend to become subdominants. Research investigating the development of compression wood may also help explain why larger trees have better stem straightness. It has been suggested that smaller, more slender trees are more likely to bend in the wind on exposed sites (Cameron and Thomas 2008), lean due to phototropic movement to exploit limited light in crowded canopies, leading to more stem deformities (Barger and Ffolliott 1976), and bend more in the wind on exposed sites (Cameron and Thomas 2008).

Larger diameter trees have bigger branches, which are detrimental to timber strength when they form a distinct whorl or are numerous within the sawn batten, yet trees with a larger DBH achieved better branch scores compared with trees with a smaller DBH. Faster growing trees have greater inter-whorl distances as well as fewer branches per whorl, which may have led to better branching scores by the assessors due to a perceived reduction in knot/surface area ratio. However, trees with large branches, or high concentrations of branches in specific locations (branch score 5 in Fig. 1), are considered to be more detrimental to timber strength than the overall number of knots (Maun 1992); hence, these trees are typically marked down in the subjective 'visual' assessment. Despite the trend between increasing diameter growth and increasing branch size $(r=$ 0.48 ), careful selection of specific families would enable gains in DBH with no increase in branch diameter relative

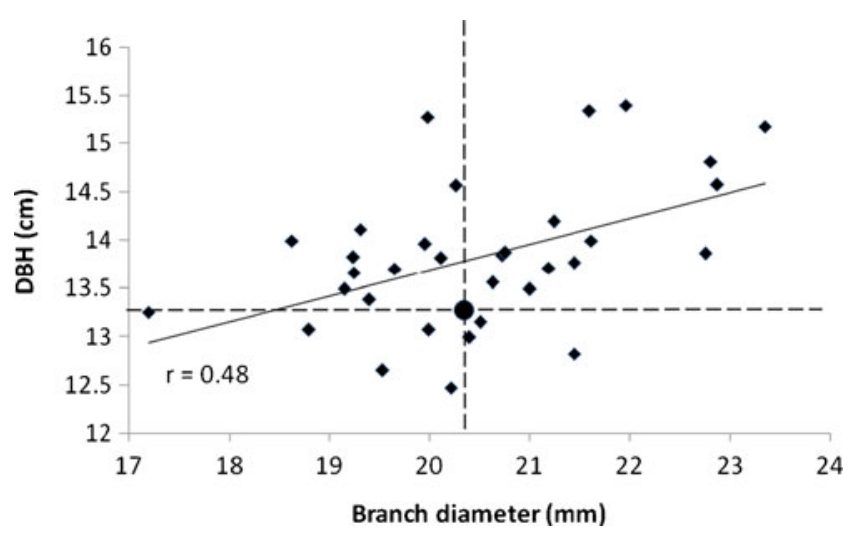

Fig. 4 Average branch diameter and DBH for the 33 families and the QCI control (solid circle). Families that may be considered for selection have a greater DBH and lower branch diameter in comparison with the QCI control (families within the top left quadrant) 
to the QCI control. Figure 4 shows the position of the QCI control and the 33 families in relation to DBH and branch diameter. Seven of the families fall below the mean DBH of the control and are unlikely to be considered for selection. The remaining families above the average DBH of the QCI control are more or less equally split between those with a lower and higher branch diameter than the control. However, $75 \%$ of the families in the top left quadrant of Fig. 4, signifying better growth rate and smaller branch diameter, are also in the upper quartile for stem score, whereas only $31 \%$ of the families are similarly represented in the upper quartile for stem score in the top right quadrant, signifying both higher growth rate and branch size. This suggests that the scoring systems used in the Sitka spruce breeding programme appear to be targeting families of good growth rate and small branch size and better stem score, indicating that co-selection for families with multiple advantageous traits is possible.

\section{Conclusions}

Moderate heritabilities and favourable genetic correlations for stem score, stem diameter and tree height should enable the selection of individuals with improved growth rate and stem straightness relative to the QCI control. Provided that a sufficiently large number of plus trees are selected for genetic testing, it should be possible to improve growth rate and reduce the number and size of branches through selection. Of the branching traits measured, greatest gains from selection can be expected for branch angle due to its strong heritability. Branch angle was not correlated with growth, enabling improvements to be made in both traits as part of a multi-trait selection programme. Although the heritability values reported here are specific to a single experiment at a single point in time, this study indicates that for most of the external stem and branching properties, the assessed heritabilities are sufficiently strong to be used as selection criteria in Sitka spruce tree improvement. The visual scoring systems used in the Sitka spruce breeding programme for stem and branching quality appear to target families of good growth rate, and the evidence from this study suggests that the current subjective scoring systems should continue to be used in the future. Tree breeders should be able to co-select for further breeding and production populations with significant advantages in all three of these traits.

Acknowledgements The authors thank the Scottish Forestry Trust for their support in funding this work. Thanks also go to Douglas Proudfoot, Institute of Biological and Environmental Sciences, University of Aberdeen, for help with felling and sample preparation.

\section{References}

Bailey JK, Feret PP, Bramlett DL (1974) Crown character differences between well-pruned Virginia pine trees and their progeny. Silvae Genetica 23:181-185

Barger RL, Ffolliott PF (1976) Factors affecting occurrence of compression wood in individual ponderosa pine trees. Wood Sci 8:201-208

Cameron AD, Thomas K (2008) Effect of thinning on the development of compression wood in stems of Corsican pine. Eur J For Res 127:247-251

Cameron AD, Lee SJ, Livingston AK, Petty JA (2005) Influence of selective breeding on the development of juvenile wood in Sitka spruce. Can J For Res 35:2951-2960

Cotterill PP, Dean CA (1990) Successful tree breeding with index selection. CSIRO, Melbourne, $80 \mathrm{pp}$

Cotterill PP, Dean CA, Van Wye G (1987) Additive and dominance genetic effects in Pinus pinaster, P. radiata and P. elliottii and some implications for breeding strategies. Silvae Genetica $36: 221-232$

Desch HE, Dinwoodie JM (1996) Timber structure, properties, conversion and use. MacMillan, London

Dinwoodie JM (2000) Timber: its nature and behaviour, 2nd edn. E \& FN Spon, New York

Doede DL, Adams WT (1998) The genetics of stem volume, stem form, and branch characteristics in sapling noble fir. Silvae Genetica 47:177-183

Ehrenberg C (1970) Breeding for stem quality. Unasylva 24:23-31

Fletcher AM, Faulkner R (1972) A plan for the improvement of Sitka spruce. Forestry Commission Research and Development Paper No. 85, HMSO, London

Haapanen M, Velling P, Annala M-L (1997) Progeny trial estimates of genetic parameters for growth and quality traits in Scots pine. Silva Fennica 31:3-12

King JN, Yeh FC, Heaman JC, Dancik BP (1992) Selection of crown form traits in controlled crosses of coastal Douglas-fir. Silvae Genetica 41:362-370

Lee SJ (1992) Likely increases in volume and revenue from planting genetically improved Sitka spruce. In: Rook DA (ed) Super Sitka for the 90s. Forestry Commission Bulletin No. 103. HMSO, Forestry Commission, Edinburgh, pp 61-74

Lee SJ (1999) Improving the timber quality of Sitka spruce through selection and breeding. Forestry 72:123-133

Lee SJ, Woolliams J, Samuel CJA, Malcolm DC (2002) A study of population variation and inheritance in Sitka spruce. II. Age trends in genetic parameters for vigour traits and optimum selection ages. Silvae Genetica 51:55-65

Macdonald E, Mochan S, Connolly T (2009) Validation of a stem straightness scoring system for Sitka spruce (Picea sitchensis (Bong.) Carr.). Forestry 82:419-429

Maun KW (1992) Sitka spruce for construction timber: the relationship between wood growth characteristics and machine grade yields of Sitka spruce. Forestry Commission Research Information Note 212. HMSO, Forestry Commission, Edinburgh, 4 pp

Merrill RE, Mohn CA (1984) Heritability and genetic correlations for stem diameter and branch characteristics in white spruce. Can J For Res 15:494-497

Patterson HD, Thompson R (1971) Recovery of inter-block information when block sizes are unequal. Biometrika 58:545-554

Samuel CJA (2007) Choice of Sitka spruce seed origins for use in British forests. Forestry Commission Bulletin 127. HMSO, Forestry Commission, Edinburgh, $175 \mathrm{pp}$

Samuel CJA, Johnston RCB (1979) A study of population variation and inheritance in Sitka spruce. I. Results of glasshouse, nursery and early forest progeny tests. Silvae Genetica 28:26-32 
Shelbourne CJA, Namkoong G (1966) Photogrammetric techniques for measuring bole straightness. Proceedings of the 8th Southern Forest Tree Improvement Conference, Savannah, GA, pp 131136

Vargas-Hernandez JJ, Adams WT, Joyce DG (2003) Quantitative genetic structure of stem form and branching traits in Douglas-fir seedlings and implications for early selection. Silvae Genetica $52: 36-44$

Velling P, Tigerstedt P (1984) Harvest index in a progeny test of Scots pine with reference to the model of selection. Silva Fennica $18: 21-32$
Venäläinen M, Pöykkö T, Hahl J (1995) The quality of young Scots pine stems in predicting breeding value. Proceedings of the 25th Canadian Tree Improvement Association, p 66

White TL, Hodge GR (1989) Predicting breeding values with applications in forest tree improvement. Kluwer Academic, Dordrecht

Williams CG, Lambeth CC (1989) Bole straightness measurements for advanced-generation loblolly pine genetic tests. Silvae Genetica 38:212-217

Williams ER, Matheson AC (1994) Experimental design and analysis for use in tree improvement. CSIRO, East Melbourne

Wright JW (1976) Introduction to forest genetics. Academic, New York 